\title{
Trabalhador Contemporâneo e Patologias por Hipersolicitação
}

\author{
Angela Peña Ghisleni ${ }^{1}$ \\ Centro Universitário Metodista IPA \\ Alvaro Roberto Crespo Merlo \\ Universidade Federal do Rio Grande do Sul
}

\begin{abstract}
Resumo
As Lesões por Esforços Repetitivos (LER)- também conhecidas como Distúrbios Osteomusculares Relacionados ao Trabalho (DORT) e que se tornaram visíveis a partir da entrada da reestruturação produtiva- são vivenciadas por trabalhadores e expressam um dos sofrimentos advindos da relação do trabalhador com o trabalho. Buscamos neste artigo a compreensão de como as LER/DORT podem desenvolver-se no corpo do trabalhador contemporâneo com base em sua história de trabalho, pensando esta síndrome como uma subjetivação da relação entre o trabalhador e o trabalho. Esta pesquisa apresenta como proposta associar conhecimentos da área biomédica com conhecimentos da psicologia social, configurando uma abordagem interdisciplinar na busca de uma linguagem de interface entre profissões que possuem o mesmo enfoque - o trabalhador.
\end{abstract}

Palavras-chave: Lesões por esforços repetitivos (LER); distúrbios osteomusculares relacionados ao trabalho (DORT); trabalho contemporâneo; subjetivação.

\section{Contemporary Worker and Work-related Musculoeskeletal Diseases}

\begin{abstract}
Cumulative Trauma Disorders (CTD) - which are also known as Work-Related Musculoeskeletal Disorders (WRMD) and have stood out since an economic system rose based on production restructuring- are faced by workers and express suffering stemming from the relations between workers and work. We look into how CTD/WRMD develop in contemporary workers' body, taking account of their work history and viewing such syndromes as the subjectivation of the relation between workers and work. We favor an interdisciplinary approach based on both the biomedical knowledge and the social psychology, in search for an interface language among the professions that have the same focusthe worker.

Keywords: Cumulative trauma disorders (CTD); work related musculoeskeletal disorders (WRMD); contemporary work; subjectivation.
\end{abstract}

As Lesões por Esforços Repetitivos (LER), também conhecidas como Distúrbios Osteomusculares Relacionados ao Trabalho (DORT), ou ainda, como Patologias por Hipersolicitação, tornaramse uma epidemia a partir da entrada nos processos produtivos do modelo de acumulação flexível, da reestruturação produtiva e da terceirização e são ainda alvo de muitos questionamentos. São afecções ocupacionais que expressam um dos sofrimentos advindos da relação do trabalhador com o trabalho e que já podem ser consideradas uma epidemia de saúde pública. As LER/DORT abrangem quadros clínicos do sistema músculoesquelético adquiridos pelo trabalhador submetido a determinadas condições de trabalho e não há uma causa única para sua ocorrência. São fatores predisponentes a repetitividade de movimentos, a manutenção de posturas inadequadas por tempo prolongado, o esforço físico, a invariabilidade de tarefas, a pressão mecânica sobre determinados segmentos do corpo (em especial membros superiores), o trabalho muscular estático, fatores organizacionais do trabalho e fatores psicossociais (Kuorinka \& Forcier, 1995).

Sabe-se, portanto, que essas lesões estão relacionadas com as condições de trabalho, porém, alguns trabalhadores desenvolvem essas afecções e outros, que realizam as mesmas atividades sob as mesmas condições organizacionais, não as desenvolvem. Pode-se pensar que um trabalhador é fisicamente mais forte que o outro e que é preciso, portanto, fortalecer a musculatura dos trabalhadores para prevenir e/ou tratar os distúrbios.

${ }^{1}$ Endereço para correspondência: Rua Assunção, 370, 201, 91050 130, Bairro Jardim Lindóia, Porto Alegre, RS. Fone: (51) 99714290.E-mail: angelag.ez@terra.com.br
Mas que dizer quando ocorre o contrário, quando o trabalhador com uma musculatura mais desenvolvida for o portador dessa síndrome? Pode-se ainda pensar que esse trabalhador possui problemas psicológicos, familiares, pessoais, tornando-o propenso a tais distúrbios. E quando os trabalhadores lesionados possuem uma história familiar e pessoal equilibrada? Qual seria a razão dessa diferença, levando uns a desenvolverem o distúrbio e outros não?

É com base nestas questões que se propõe este artigo. Visualizando o trabalhador como um todo, com corpo físico e mental não dicotomizado, propomos a compreensão de como podem desenvolver-se as LER/DORT no corpo deste trabalhador contemporâneo a partir de sua história de trabalho, pensando essa síndrome como uma subjetivação.

\section{Método}

$\mathrm{Na}$ tentativa de encontrar respostas para as questões acima expostas, foram analisados relatos de 50 trabalhadores portadores de LER/DORT, pacientes do Ambulatório de Doenças do Trabalho do Hospital de Clínicas de Porto Alegre (ADT-HCPA), onde as LER/DORT correspondem a 70\% dos diagnósticos ali realizados (Mello, Pozza, Sebben \& Vieira, 2001).

Trata-se, portanto, de uma pesquisa qualitativa, em que os relatos foram obtidos por meio de entrevistas semi-estruturadas. Como característica desse instrumento, apesar de seguir um roteiro (na forma de uma ficha de entrevista) como referência que conduzia a um levantamento da história profissional e da doença desses trabalhadores, foi respeitada a singularidade de cada entrevistado, possibilitando a cada um a abertura para 
abordar questões que porventura não estivessem previstas. Foram também realizadas avaliações físicas, objetivando uma maior apropriação do quadro clínico dos trabalhadores, de modo a possibilitar traçar um perfil clínico de suas LER/DORT. A execução dessa pesquisa foi previamente autorizada pelo Comitê de Ética em Pesquisa do HCPA.

O objetivo da pesquisa foi investigar como se desenvolvem as LER/DORT no corpo desse trabalhador, a partir de sua história de trabalho, visualizando essa síndrome como uma subjetivação da relação entre o trabalhador e o trabalho.

Em Vigiar e Punir (1988), Foucault introduz a palavra genealogia ao suscitar o problema do poder e do corpo e também o exercício do poder sobre o corpo. De acordo com o autor, genealogia é :

o conjunto de pesquisas que busca redescobrir as lutas, e as memórias brutas dos combates, no acoplamento entre o saber erudito e o saber desqualificado. É a busca do saber histórico da luta. Essa pesquisa só pode ser realizada ao eliminarmos a tirania dos discursos englobantes, e a constituição de um saber histórico das lutas, acoplando conhecimento com memórias locais. Trata-se de ativar os saberes locais, descontínuos, desqualificados, não legitimados, contra a instância teórica que pretendia depurá-los, hierarquizá-los, ordená-los em nome de um conhecimento verdadeiro, em nome dos direitos de uma ciência detida por alguns. (pp. 164)

Os relatos desta pesquisa foram analisados de acordo com as ferramentas teóricas da genealogia foucaultiana, com o intuito de fazer uma análise crítica das relações de poder e das formas de resistência aos diferentes tipos de poder que se apresentam na atualidade. Buscou-se realizar o estudo das estratégias do indivíduo, na sua constituição como sujeito, que defende a sua própria singularidade em meio ao atravessamento das redes de poder.

Deleuze (1990) diz que, ao fazermos um mapa, percorremos terras desconhecidas e temos que entrar nelas e deixar-nos atravessar, deixar-nos ser arrastados pelas correntes para encontrarmos novas orientações. Esta pesquisa pretende, por meio dos relatos, encontrar novas orientações, novos caminhos possíveis para a compreensão do processo de subjetivação das LER/DORT no trabalhador contemporâneo.

Fundamentalmente, a pesquisa apresenta como proposta associar conhecimentos da área biomédica com conhecimentos da psicologia social, configurando uma abordagem interdisciplinar. As LER/ DORT constituem um caso bastante importante e privilegiado para esse objetivo, já que são estudadas em campos multiprofissionais, o que obriga a criar uma linguagem de interface entre profissões e configurar um campo de práticas interdisciplinares com o mesmo enfoque - o trabalhador.

\section{Resultados}

Perfil

A característica marcante dos trabalhadores estudados era determinada pelo gênero, pois $80 \%$ eram do sexo feminino, $52 \%$ estavam na faixa etária de 36 a 46 anos de idade e $62 \%$ tinham ensino fundamental incompleto.
Das 29 profissões encontradas, 16 estavam relacionadas com o trabalho em linha de produção. As de maior freqüência foram o ramo calçadista $(26 \%)$, o ramo da limpeza $(12 \%)$, as cozinheiras $(8 \%)$ e as costureiras (6\%). Quanto à carga horária, $72 \%$ trabalhavam de 8 a 9h/dia. Dos 50 entrevistados, $30 \%$ realizavam horas-extras e apenas $16 \%$ tinham o direito a pausas durante a jornada de trabalho.

Verificou-se que $60 \%$ dos pesquisados iniciaram suas vidas profissionais no período de 5 a 15 anos de idade (período considerado trabalho infantil). No que se refere à situação profissional, $78 \%$ estavam afastados do trabalho para tratamento. Em relação ao tempo de permanência no último emprego até o momento do afastamento, da demissão ou ainda, no caso dos que estavam trabalhando, até o dia da entrevista, $64 \%$ trabalharam de 2 meses a 5 anos. Observou-se também que $44 \%$ dos trabalhadores adoeceram em um período de 2 a 10 anos de trabalho.

\section{Exame Físico}

Uma característica marcante desses trabalhadores são os traços de tensão muscular excessiva, também conhecida como contração muscular involuntária. O estado de contração muscular excessivo é devido, segundo alguns autores, a fatores psicossociais do trabalho e apresentam-se principalmente na região dos ombros e pescoço, levando o indivíduo a um quadro álgico e predispondo-o ao desenvolvimento de lesões (Couto, 1998; Moon \& Sauter, 1996). O tensionamento era possível de ser observado principalmente no relato de questões que envolvessem seus ambientes e rotinas de trabalho, a ausência de reconhecimento profissional, ou então quando falavam de suas dores, de suas limitações ou do não reconhecimento dessas mesmas dores. Tais características de tensionamento muscular excessivo apresentaram-se em $90 \%$ dos pesquisados. Durante o exame físico, uma das alterações observadas em $92 \%$ dos trabalhadores foi a presença de contraturas musculares na região da coluna cervical. $\mathrm{O}$ trabalhador que apresentou contratura muscular, mas não tinha tensionamento excessivo foi diagnosticado, no entanto, com Hérnia de Disco na coluna cervical, justificando a exceção.

Esses dados levam a pensar que o tensionamento excessivo tende a gerar contraturas musculares, geralmente na região da coluna cervical, já que se trata de uma área normalmente sobrecarregada, em termos biomecânicos, pelas atividades realizadas no trabalho com os membros superiores.

É interessante notar que apenas 5 trabalhadores tinham diagnóstico médico de cervicalgia, apesar de $92 \%$ dos entrevistados apresentarem contraturas musculares cervicais álgicas. De fato, dos 46 pacientes que apresentavam contraturas álgicas, apenas 17 deles receberam um diagnóstico que explicasse a origem do quadro (5Cervicalgia; 7-Síndrome Miofascial; 4-Fibromialgia; 1-Hérnia Discal Cervical). Os demais 29 trabalhadores que apresentaram dores e contraturas musculares na região da cervical não se enquadraram entre esses diagnósticos. É importante recordar que os médicos diagnosticam de acordo com as afecções previstas pela Previdência Social Brasileira, a qual não reconhece a Síndrome Miofascial ou a Fibromialgia, mas prevê a Cervicalgia e Cervicobraquialgia (Assunção \& Almeida, 2003).

Em relação aos diagnósticos coletados dos prontuários dos pacientes, as patologias mais freqüentes encontradas na pesquisa foram a Síndrome do Túnel do Carpo (STC) em 31 trabalhadores, 
a Síndrome do Impacto em 28 e a Epicondilite em 18. As lesões encontradas nesta pesquisa são localizadas fundamentalmente em membros superiores, o que confirma o relatado em bibliografia. Como exceção, um trabalhador apresentou Lombociatalgia e outro, Hérnia de Disco Lombar.

Utilizando uma graduação de dor de zero a 10, em que zero representaria ausência de dor e 10, uma dor insuportável, verificamos que $30 \%$ dos trabalhadores apresentavam uma dor diária graduada em nível 7 e $28 \%$ dos trabalhadores, em nível 8. A interpretação da sensação dolorosa envolve não apenas aspectos físico-químicos de captação das excitações dolorosas mediante um receptor nervoso sensitivo, mas também os componentes socioculturais dos indivíduos e as particularidades do ambiente em que o fenômeno nociceptivo é experimentado.

De acordo com referencial teórico de Assunção (1995), foi possível classificar as LER/DORT dos entrevistados em estágios, configurando $70 \%$ dos entrevistados no estágio máximo, conhecido como fase 4 das LER/DORT. O referido estágio se caracteriza pela impossibilidade de realizar tarefas domésticas e de trabalho, pela dificuldade de dormir devido à dor, por exacerbação da dor e edema, pela limitação dos movimentos, por força muscular diminuída, atrofia e/ou deformidades.

\section{Relatos}

Os trabalhadores apontaram os fatores organizacionais como um dos principais responsáveis pelo desenvolvimento das LER/ DORT, pois, como eles não têm liberdade para gerenciar suas atividades, foram levados: a submeter-se a horas extras, provocando jornadas de trabalho extensas; a realizar atividades repetitivas com ritmos produtivos elevados; a trabalhar em postos de trabalho sem dispositivos facilitadores na linha produtiva; a permanecer em ambientes de trabalho inadequados, com baixa iluminação ou excesso de calor ou frio; a realizar esforços excessivos, bem como a manter as mesmas posições corporais por períodos demasiado longos; a sofrer o acúmulo de funções com a exploração de suas habilidades, configurando excesso de trabalho; e a dedicar-se ao trabalho de forma abusiva na busca pelo reconhecimento. Conforme uma operadora de telemarketing:

O ambiente era de uma cobrança muito grande, tudo com meta pra atingir. Tanto que da minha época, e faz 2 anos que eu tô afastada, se eu voltar lá não tem mais nenhum funcionário que trabalhava comigo. Porque é assim, tu não atingiu a meta, 3 meses e tchau pra ti. Tão te desligando porque tu não tá produzindo. Tu te estopora todo, te arrebenta pra manter o emprego e ganhar um pouco mais. Porque era assim, vinha de cima a pressão, mas tinha o supervisor que ficava em cima com aquela cobrança, ficava perguntando: 'E daí, como é que tá?’. Eu não sei como é que eu agüentei tanto tempo

Percebeu-se que esses trabalhadores convivem diariamente com as pressões por produtividade por meio da competição entre colegas, das pressões da chefia, do ganho salarial por produtividade, das reuniões com ameaça de demissão e das premiações dos programas de qualidade. São trabalhadores que procuram dar conta de um trabalho cada vez maior, com um número de colegas cada vez menor e que, em sua maioria, não têm o direito de organizar suas atividades e não têm liberdade criativa e inovadora em suas funções. Estamos diante de trabalhadores que utilizam seus corpos como reguladores para vencer as dificuldades impostas pela organização do trabalho e pelos processos produtivos. Segundo uma confeccionadora de esponjas: Eu produzia mais que os outros, porque se a gente não fizesse isso, não ganhava cesta básica, não ganhava tanto por cento a mais... porque eles querem pessoas que produ:

É possível observar que o mundo profissional desses trabalhadores está caracterizado pela mescla da flexibilidade da reestruturação produtiva com o método taylorista/fordista. Como afirma Foucault (1999), na técnica de regulação, a disciplina não é excluída e sim integrada. Verificam-se nesses trabalhadores corpos dóceis, moldados, transformados em força útil e, ao mesmo tempo, corpos flexíveis, maleáveis, capazes de adaptarse a qualquer situação imposta, mesmo que a adaptação exija um adoecimento. Observa-se no relato de uma trabalhadora de industrialização de alimentos a tentativa de adaptação aos novos processos de organização do trabalho:

Isso foi uma mudança muito rápida, sabe?, velocidade nos fornos, mudaram também o nosso biscoito, decidiram por uns pequenininhos. Meu Deus do céu, complicadíssimos para trabalhar, terríveis, porque eles se desmanchavam em cima da mesa. Então inventaram novas formas de trabalhar e queriam que o pique fosse o mesmo. Foi aí que eu senti. Foi quando eu fui me entregando, não fui agüentando.

O conceito de trabalho desses indivíduos carrega um código moral configurado por uma ética. A ética do trabalho, entendida como um "regime de verdade", apresenta tanto a função social de constituir os processos identificatórios, que dão sentido à própria existência, como a função de legitimar as formas de dominação do capitalismo (Nardi, 2002). Dessa forma, mediante o "regime de verdade" do trabalho, os indivíduos entrevistados demonstram que é por meio do trabalho que eles podem suprir necessidades construídas pelo próprio capitalismo, podendo, assim, alcançar objetivos como a aquisição de moradia, de utensílios domésticos e de outros objetos consumíveis, assim como podem ser integrados à sociedade e ainda ter prazer em suas atividades profissionais. Pode-se ver o conceito de trabalho de acordo com a mesma trabalhadora acima citada:

Trabalho, prá mim, é uma coisa que traz dignidade prá pessoa, faz a pessoa se sentir bem, valorizada. $\mathrm{E}$ a dignidade é uma coisa que te eleva. Agora que eu não tô trabalhando, eu me sinto uma inútil, então o trabalho faz a pessoa ser gente, que faz ter sonhos, idéias, vou construir, vou fazer, vou ajudar meus filhos.

A identidade de trabalhador, de acordo com Guattari (1986), está ligada à busca pelo reconhecimento social de uma pessoa. Ao analisar as falas dos entrevistados, percebe-se que todos carregam o traço identificatório de pessoas trabalhadoras. É por meio do trabalho que essas pessoas vêem a possibilidade de pertencimento a uma comunidade ou grupo social. Algumas relatam que são trabalhadoras em função da educação que receberam na infância, predefinindo suas maneiras de ser. Guattari (1986) aponta que a identidade é configurada com base em uma produção da subjetividade capitalística através dos sistemas de conexão com as máquinas de controle social. O que se observa é uma perpetuação de subjetividades serializadas, 
normatizadas, que se estenderam de pais/mães para filhos (as). Uma trabalhadora de limpeza disse: Eu me irrito porque en sempre trabalhei e en não consigo mais. Eu me criei sempre trabalhando, dai é difíicl não ser mais assim.

Socialmente, a doença é aceita como uma explicação do porquê de não trabalhar mais, preservando a identidade de trabalhador e mantendo os atributos morais que lhe são associados de ser ativo, forte, honesto, bravo (Jacques, 2002). Para os entrevistados, o adoecimento ameaça a identidade de trabalhador, já que se apresenta como uma maneira de retirar o pouco reconhecimento que a sociedade oferece. Eles relataram serem trabalhadores dedicados e não entenderem a razão de não conseguirem mais trabalhar. A doença, para eles, não os libera das práticas profissionais. Eles permanecem impulsionados a manter-se trabalhando, presos à dominação capitalista produtiva, visto que essa é a única maneira de darem sentido às suas existências, permanecerem integrados à sociedade e serem cidadãos. Conforme uma secretária: Quando a empresa determinou que eu devia me afastar, pra mim foi horrivel, me arrasou de todas as ordens, tanto emocional, quanto financeira, porque en gostava daquilo, era como se tivessem me tirado o pão da boca, o ar que eu vivo.

No processo de formação da identidade de trabalhador, carregase na memória a promessa de ser confiável, honesto, dedicado, enfim, ser "trabalhador". A carga da responsabilidade que se assume é uma característica dessa identidade. Se, por algum motivo, não conseguir cumprir sua promessa, como no caso do adoecimento, o trabalhador sente-se culpado e em dívida (Nietzsche, 1998). Essas características dos entrevistados, de serem dedicados e responsáveis, podem ser pensadas com base no que diz Nietzsche a respeito da origem da responsabilidade. Para esse autor, no momento em que o homem é capaz de fazer promessas e tornar-se necessário, confiável, dentro do que se chama de uma "moralidade do costume", ele torna-se um devedor. Para infundir confiança e garantir seriedade, empenha aquilo sobre o qual ainda tem poder, como seu corpo, sua liberdade ou até mesmo sua vida. Segundo uma tecelã:

Se desse uma peça errada, tinha bronca. Só que eu nunca errei, fazia tudo certo. As que erravam escondiam as peças erradas. Daí as que não erravam entregavam pro patrão e as que escondiam eram demitidas. Eu entregava. Foi aí que a malharia foi crescendo. Nós fomos arrumando a malharia. Eles diziam que não iam valorizar se fizesse mais peça, porque eles queriam o teto, mas eu ficava chateada porque eu queria, no mínimo, um elogio deles.

De acordo com Sant'Anna (2001), vivemos um período no qual quanto mais as pessoas forem alvo de coações, de explorações comerciais, forçadas a ampliar recordes de consumo e rentabilidade, mais ficam carentes de reconhecimento, de cuidados e de afeto. Para a autora, vivemos em uma época de miséria de afeto pelo outro. Observa-se que uma das maneiras de busca de reconhecimento e de afeto é pelo trabalho.

O fator motivacional desses trabalhadores pesquisados, para produzirem cada vez mais, era a possibilidade de serem reconhecidos, valorizados, e, ao não conseguirem esse retorno nos locais de trabalho, desenvolveram mágoas, ressentimentos. Constataram-se pessoas ressentidas por terem empregado todas as suas forças em determinadas tarefas e que, em troca de sua saúde, ganhavam salários defasados e ambientes sem condições de trabalho, na maioria das vezes sem receber o devido respeito como indivíduos e como profissionais.

O reconhecimento profissional nas falas dos trabalhadores se traduz em reivindicações por respeito, salário justo, um ambiente de trabalho bom, direito a pausas, valorização de suas funções e uma diminuição dos ritmos de trabalho impostos. O que esses trabalhadores reivindicavam era a diminuição da pressão exercida sobre eles diariamente pelas empresas para atingir níveis de produtividade cada vez maiores e com melhor qualidade. Em suas falas reside uma contradição: queixam-se da pressão para atingir níveis cada vez mais altos de qualidade e produtividade, mas aumentam espontaneamente suas cargas produtivas para chamar a atenção da chefia em busca de reconhecimento. De acordo com uma costureira de calçados:

Reconhecimento é pagar um pouco melhor, fazer o ambiente de trabalho se tornar um pouco melhor. Porque lá era muito tumulto, sabe? O gerente era muito estúpido com as pessoas. A gente ficava propriamente nervosa, porque ele já vinha xingando, e daí de tão nervosa tu não conseguia mais trabalhar direito. Sei lá, podia dar uns minutos pras pessoas descansar, né? Porque daí as pessoas vão com tudo trabalhar.

Nos relatos das entrevistas desta pesquisa pode-se perceber, nas exigências diferenciadas impostas nas relações e organizações sexuais do trabalho, o porquê de as mulheres serem maioria nas estatísticas referentes às LER/DORT. Muitas delas eram chefes de familia, responsáveis pelo sustento da casa e pela criação de seus filhos, e tinham que permanecer trabalhando, fazendo horas extras, tanto para dar conta de uma produção como para melhorar seu salário, visando a oferecer melhores condições de vida para seus filhos. Trabalhavam, muitas vezes, preocupadas por deixarem seus filhos sozinhos e eram ainda responsáveis pela manutenção da casa, o que configurava uma dupla jornada. Algumas eram autônomas, realizando suas atividades profissionais em casa, intercaladas com as responsabilidades do lar e dos filhos. Quando trabalhavam em empresas, eram obrigadas a demonstrar dedicação maior que os colegas homens, pois tinham que comprovar suas competências. Como disse uma costureira:

Eu dava aquele pique na casa de manhã e de tarde eu pegava na costura e ia até 2 horas da manhã, tranqüilamente, conforme fosse $o$ pedido. Eu fazia intervalos durante a costura prá cuidar das lições da escola da filha, prá fazer janta, prá atender a casa um pouco. Eu não parava e voltava pro atelier de novo.

Esses trabalhadores inicialmente tensionavam-se apenas em seus locais de trabalho, na tentativa de dar conta de um volume produtivo. Eles não podiam parar, tinham que alcançar a meta do dia com alto padrão de qualidade, administrar a pressão da chefia e conviver com o medo da demissão. Eles ficavam em estado de prontidão, prontos para resolver algum problema, eram ágeis, rápidos para tomadas de decisão que não interrompessem a produção. Esse estado de prontidão exigia da musculatura um grau de tensionamento constante que lhes garantisse a prontidão também do músculo, para qualquer eventualidade. A tensão acumulava-se no decorrer do dia de trabalho e, no caso da mulher, ao chegar em casa, antes de tentar relaxar, ainda tinha que dar conta da manutenção da casa e do cuidado dos filhos, muitas vezes seguindo o mesmo ritmo que a empresa havia imposto. 
Como um efeito cumulativo de tensionamentos, chegaram ao estágio em que não se tratava apenas de estarem tensas, mas sim de serem tensas. Relataram que, ao menor estímulo, tanto físico por algum esforço como psíquico por alguma preocupação, os tensionamentos pioravam, gerando cada vez mais dores. De acordo com uma forjadora:

Eu trabalhava com os músculos sempre tensa, porque, em primeiro lugar, não pode parar uns minutos pra relaxar e, em segundo lugar, não tem liberdade. Porque se a mente não tiver dizendo que tem o direito de relaxar, ninguém vai relaxar. Eu não sentia que podia relaxar. Eu tinha que trabalhar e seguir em frente. Eu terminava o dia tensa. Daí ia pra casa, fazia as coisas da casa e ia pro meu banho. Porque daí a mente vai descansar. Não adianta o corpo ir descansar se a mente não tá tranqüila. Eu acho que as duas coisas têm que estar de comum acordo, mente e corpo, prá ficar descansada. Nos últimos tempos eu não conseguia mais descansar, nem corpo nem mente.

Os trabalhadores, presos às suas vivências profissionais, após serem afastados de suas atividades, passam o tempo em casa revivendo tais vivências, tendo suas dores intensificadas. Um dos fatores desencadeadores deste processo de lembrança das vivências profissionais ocorre ao perceberem as limitações de suas normas de vida decorrentes do adoecimento. A incapacidade de realizarem atividades que sempre haviam desempenhado reforça na consciência essas memórias. A dor diária impede-os de esquecer as vivências, fazendo deles corpos presos às suas consciências, impossibilitados de viverem o novo sem o contaminar com o velho. Deleuze e Guattari (1996) e Gil (1997) apontam que corpos presos às suas consciências deixam de ser lugares de passagem do inconsciente, de passagem para novos afetos, de novas intensidades, e passam a ser corpos presos a um organismo, sedimentado, com formas e funções determinadas. Conforme o relato de uma calçadista: Quando eu tento fazer uma coisa e não consigo, aquilo me deixa desatinada. Dai eu tenho que tomar um calmante. A dor fica até quatro vezes maior, parece que, quando eu fico assim, mexe alguma coisa no corpo que piora.

Os trabalhadores adoecidos cronicamente apresentam grande dificuldade de recuperação de suas lesões. Entre os motivos verificados para tal dificuldade, encontramos a própria cronicidade, a falta de assistência e, além disso, a dificuldade de esquecimento das situações traumáticas vividas. Não lhes basta parar de trabalhar, ser medicados ou ver suas dores tratadas, eles precisam esquecer suas vivências afetivas. A cada tentativa frustrada de realizar alguma atividade ou a cada vez em que se deparam com uma tarefa que já sabem não poder nem tentar realizar, esses trabalhadores apresentam um quadro de depressão, com a elevação do grau de tensionamento e com um conseqüente agravamento de suas dores. O tensionamento parece estar na memória corpórea desses trabalhadores. Quando a memória é provocada por uma limitação ou por uma dor, o tensionamento aumenta como uma maneira de reforço de sua consciência.

\section{Discussão e Considerações Finais}

Os trabalhadores entrevistados relataram histórias profissionais semelhantes no que se refere a processos produtivos intensos, à pressão por produtividade com intensificação dos ritmos de trabalho, somados a esforços intensos e movimentos repetitivos, com postos de trabalho ergonomicamente inadequados, assim como instrumentais de trabalho inadequados. Trabalharam, principalmente, de maneira não apenas extensiva em longas jornadas de trabalho, como também de maneira intensiva, dedicando-se ao máximo para alcançar as metas propostas. Esses trabalhadores, para darem conta do ritmo produtivo, acabaram utilizando seus corpos como o único componente sobre o qual tinham algum controle.

Foram exigidas competências desses trabalhadores que requeriam o envolvimento de suas subjetividades. Essas competências envolviam a capacidade de competir, de adaptar-se à intensificação dos ritmos de trabalho e de inserir-se em situações novas que as empresas estabeleciam.

As exigências atuais podem ser compreendidas por intermédio dos conceitos de Negri (2001) acerca do trabalho imaterial. O trabalho imaterial não é apenas intelectual, mas também afetivo. Negri afirma que a ferramenta de trabalho hoje está encarnada no corpo e envolve tudo o que pertence ao "sentir". Para essa teoria, o trabalho constróise baseado nas relações de afeto que os corpos utilizam colocando em produção a própria vida. É através de “trocas" afetivas, realizadas por meio da linguagem e da comunicação, que as relações de trabalho se configuram.

Quando os trabalhadores empregam suas competências na produção, envolvendo tudo o que pertence ao "sentir", eles não as utilizam de maneira autônoma na realização das tarefas. Ao contrário, suas habilidades são absorvidas pela produção como uma característica exigida por aquele posto de trabalho, como algo prescrito e pressuposto. Dessa forma, o capital apropria-se da subjetividade dos trabalhadores como instrumentos de trabalho.

Se a subjetividade dos trabalhadores age na formação das relações do trabalho, o trabalho também atua na formação das subjetividades. Para Rolnik (1995), na subjetividade há uma textura ontológica que se vai fazendo de fluxos e partículas que constituem nossa composição atual e que se conecta com outros fluxos e partículas com os quais coexistem, somando-se e produzindo outras composições. Tais composições provocam um rompimento dos contornos da nossa figura subjetiva atual. A cada vez que isso acontece, há uma violência vivida por nosso corpo em sua forma atual, que nos desestabiliza e nos exige a criação de um novo corpo. $\mathrm{O}$ corpo traz para o visível a diferença que encarnou em nós e que nos tornou outro.

Pelbart (1989) considera subjetividade como uma modalidade de inflexão das forças do fora, movimento esse que cria um interior. O interior encerra dentro de si o fora com suas partículas desaceleradas conforme um ritmo próprio e uma velocidade específica. Mas subjetividade não pode, segundo o autor, ser uma interioridade fechada sobre si mesma e contraposta ao exterior, feito uma cápsula hermética flutuando num fora indeterminado. Subjetividade é uma inflexão do próprio fora, é uma dobra do fora.

Deleuze (1992) afirma que, no poder, encontramos a relação das forças com outras forças, que, na subjetivação, trata-se da dobra da força, e que, conforme a maneira de dobrar a linha da força, constituímo-nos como modos de existência ou como invenção da vida. Inventando modos de vida, somos capazes de resistir ao poder, bem como de transformar o saber, mesmo que um tal saber tente penetrar-nos ou um poder apropriar-se de nós. 
Portanto, a subjetivação é o dobrar das forças do fora, é um regime de regulação dos fluxos que permitem ou não determinados acoplamentos com o trabalho, que não constitui o sujeito, mas cria modos de existência. A produção de subjetividade "capitalística" que produz indivíduos normalizados configura a identidade de trabalhador, determinando os modos de ser e de trabalhar (Deleuze, 1992; Guattari, 1986).

Neste estudo, observa-se de maneira acentuada o traço identificatório de trabalhador nos entrevistados. Tal identificação, constituída pela "produção de subjetividade capitalística", determina os modos de existência e favorece o regime produtivo intensivo. $\mathrm{O}$ modo de existência apresenta-se de tal maneira que, apesar de os entrevistados estarem adoecidos, eles permanecem impulsionados a continuar trabalhando. Tendo o trabalho como o único meio de estarem integrados à sociedade, eles permanecem presos a essa identificação, o que acaba gerando sofrimento, já que não conseguem realizar suas atividades.

Se a identidade de trabalhador é constituída no reconhecimento do outro (Guattari, 1986), com a doença os trabalhadores vêem ameaçadas suas identidades ao serem discriminados por seus pares por estarem doentes. Mesmo com a identidade de trabalhador ameaçada pela doença, os entrevistados demonstraram estar "anestesiados" e deixam vibrar em suas peles apenas o que não desestabilize seus vícios de identidade (Rolnik, 1995).

Como característica desta subjetividade "capitalística" produzida, encontramos a tensão muscular excessiva determinando não apenas os modos de trabalhar, como também os modos de ser. A tensão excessiva de indivíduos com fatores psicossociais ativos é uma contração muscular estática que gera um aumento da pressão intramuscular, levando à compressão dos vasos sangüíneos intramusculares. Dessa forma, a nutrição da musculatura pode ficar perturbada, especialmente quando a contração for elevada, ocasionando um déficit de oxigênio (uma isquemia) que obriga o músculo a trabalhar em condições anaeróbicas com um conseqüente acúmulo de ácido lático, irritante poderoso das terminações nervosas de dor (nociceptores), o que leva à fadiga muscular (Assunção \& Almeida, 2003; Ranney, 2000). Couto (1998) aduz que esse estado de tensão muscular excessivo predispõe o trabalhador ao desenvolvimento de lesões.

Verifica-se, com base na alta freqüência da tensão muscular excessiva nos trabalhadores entrevistados, que as LER/DORT podem ter sua origem nesses tensionamentos, podendo ser o elemento diferencial de por que outros não adoecem realizando as mesmas atividades. Podemos ainda concluir que os problemas de reabilitação dos trabalhadores poderiam estar relacionados com a dificuldade de libertar-se do estado de tensão excessivo permanente, o que impediria a recuperação de uma estrutura lesionada.

Ao analisar os trabalhadores portadores de LER/DORT, procuramos fazê-lo com base em suas histórias profissionais, entendendo seus acometimentos como processos de subjetivação das relações entre o trabalhador e o trabalho que demonstram espaços de transformação, e, acima de tudo, quisemos pensar esse problema de maneira que permitisse ir além das evidências que constituem o senso comum. Mas o fato é que muito ainda resta a ser estudado e pesquisado acerca desses trabalhadores adoecidos. $\mathrm{O}$ que se pode afirmar é que estamos diante de acometimentos já considerados epidêmicos e que exigem a atenção de profissionais de vários campos de trabalho. Esta pesquisa, na tentativa de aproximar áreas de atuação, reforça a importância de pesquisas com enfoque interdisciplinar que possibilitem encontrar meios para auxiliar esses trabalhadores.

\section{Referências}

Assunção, A. A. \& Almeida, I. M. (2003). Doenças osteomusculares relacionadas com o trabalho: Membro superior e pescoço. Em R. Mendes (Org.), Patologia do trabalho (pp. 1501-1539). Rio de Janeiro: Atheneu.

Assunção, A. A. (1995). Sistema músculo esquelético: Lesões por esforços repetitivos (LER). Em R. Mendes (Org), Patologia do trabalho (pp. 173-198). Rio de Janeiro: Atheneu.

Couto, H. A. (1998). Fatores causadores das lesões de membros superiores. Em H. A. Couto, S. J. Nicoletti \& O. Lech (Orgs.), Como gerenciar a questão das LER/DORT (pp. 67-112). Belo Horizonte: Ergo.

Deleuze, G. (1990). Michel Foucault, filósofo. Barcelona: Gedisa.

Deleuze, G. (1992). Conversações. São Paulo: Ed. 34.

Deleuze, G. \& Guattari, F. (1996). MilPlatôs (Vol. 3). Rio de Janeiro: Ed.34.

Foucault, M. (1988). Vigiar e Punir: História da violência nas prisões. Petrópolis, RJ: Vozes.

Foucault, M. (1999). Em defesa da sociedade. São Paulo: Martins Fontes.

Gil, J. (1997). Metamorfoses do corpo. Lisboa: Relógio D’Água.

Guattari, F. \& Rolnik, S. (1986). Micropolitica: Cartografias do desejo. Petrópolis, RJ: Vozes.

Jacques, M. G. (2002). Doença dos nervos: Uma expressão da relação entre saúde/ doença mental. Em M. G. Jacques \& W. Codo (Orgs.), Saúde mental e trabalho: Leituras (pp. 98-111). Petrópolis, RJ: Vozes.

Kuorinka, I. \& Forcier, L. (1995). Work-related muskuloskeletal disorders (WMSDs): A reference book forprevention. Great Britain: Taylor \& Francis.

Mello, P., Pozza, M., Sebben, J. C. \& Vieira, M. H. B.(2001). Perfil de demanda do ambulatório de doenças do trabalho do Hospital de Clínicas de Porto Alegre. Monografia de Conclusão de Curso não-publicada, Curso de Especialização em Medicina do Trabalho, Universidade Federal do Rio Grande do Sul. Porto Alegre, RS.

Moon, S. D. \& Sauter, S. L. (1996). Beyond biomechanics: Psychosocial aspects of musculoeskeletal disorders in office work. London: Taylor \& Francis.

Nardi, H. C. (2002). Trabalho e ética: Os processos de subjetivação de duas geracõos de trabalhadores metalúrgicos e do setor informal. Tese de Doutorado não-publicada, Curso de PósGraduação em Sociologia, Universidade Federal do Rio Grande do Sul. Porto Alegre, RS.

Negri, T. (2001). Exilio: Seguido de valor e afeto. São Paulo: Iluminuras.

Nietzsche, F. (1998). Genealogia da moral: Uma polêmica. São Paulo: Cia das Letras.

Pelbart, P. P. (1989). Da clausura do fora ao fora da clausura: Loucura e desraz̃ão. São Paulo: Brasiliense.

Ranney, D. (2000). Distúrbios osteomusculares crônicos relacionados ao trabalho. São Paulo: Roca. Rolnik, S. (1995). Subjetividade, ética e cultura nas práticas clínicas. Cadernos de Subjetividade/ PUC-SP, 3, 305-313.

Sant'Anna, D. B. de (2001). Corpos de passagem: Ensaios sobre a subjetividade contemporânea. São Paulo: Estação Liberdade.

Recebido: 29/09/2003

$1^{a}$ Revisão: 05/01/2004

Última Revisão: 07/04/2004

Aceite Final: 14/04/2004

Sobre os autores

Ângela Peña Ghisleni é Fisioterapeuta, Mestre em Psicologia Social e Institucional pela Universidade Federal do Rio Grande do Sul e Professora do Centro Universitário Metodista IPA.

Álvaro Roberto Crespo Merlo é Médico, Doutor em Sociologia e Professor do Programa de Pós-graduação em Psicologia Social e Institucional e em Epidemiologia na Universidade Federal do Rio Grande do Sul. 